\title{
ESPECTÁCULOS POPULARES COMO ESCORZOS NARRATIVOS EN NEVILLE: CINE, TOROS Y TEATRO
}

\author{
Gregorio Torres Nebrera \\ Universidad de Extremadura
}

En la narrativa española del medio siglo (entre el año 45 y el 60) es dado distinguir un grupo de autores y textos que, vinculados casi siempre a ciertas publicaciones humorísticas del momento, integraron un homogéneo grupo de «novelas y novelistas de humor» que debe considerarse como una restauración de aquel otro grupo de finales de los años veinte y comienzo de los treinta que, al amparo de Ramón y -más cercanamente- de Jardiel, buscó una dirección humorística para la narrativa de vanguardia, como manifiesta alternativa a la «novela social», las dos opciones en las que, forzosamente, habían de resolverse las deshumanizadas narraciones (Jarnés, Ayala, Espina, Chacel, Salinas...) que propició Ortega y su Revista de Occidente. A la relación que ofrecía el catálogo de Biblioteca Nueva (en su colección Grandes Novelas Humorísticas) con nombres como Juan José Domenchina (La túnica de Neso, 1929), Samuel Ros (El ventrículo y la muda-1930- y El hombre de los medios abrazos, 1932), Tirso Medina (Mis dos mitades, 1929) Antoniorrobles (Novia, partido por dos -1929-y Torerito soberbio,1932) y toda la serie magistral de Jardiel (desde Amor se escribe sin hache a La tournée de Dios), hay que sumar otros nombres y títulos (aunque no aparecieran en la mencionada colección de Biblioteca Nueva) como Felipe Ximénez de Sandoval (Tres mujeres más equis, de 1930) o Roque Six, la única novela del dramaturgo José López Rubio, aparecida en las prensas de Caro Raggio, y una de las más notables narraciones de la serie humorística de la preguerra. Serie en la que, por supuesto, 
ya había colocado su aportación notabilísima Edgar Neville con Don Clorato de Potasa, también en la colección Grandes Novelas Humorísticas y en 1929, una excelente novela -la primera en su lista particular- de la que aquí y ahora solo quiero recordar su subtítulo seriamente elocuente («Andanzas de un hombre que se reía mucho de todo») y su triple dedicatoria: «A mis tres grandes amigos Charles Chaplin, RAMON y Juan Belmonte», una dedicatoria en la que ya estaban presentes dos aficiones y dos de los tres espectáculos que en este ensayo se consideran: el cine y los toros; el teatro estaba a punto de llegar a la vida y a la obra de Edgar Neville ${ }^{1}$.

En efecto, con unos preliminares que se llamaron Miquelarena (Don Adolfo el libertino, 1940) y Villalonga (Mis Giacomini, 1941), la novela de humor remontó vuelos en los años cuarenta y cincuenta, siendo precisamente Neville, superviviente del grupo anterior, uno de sus principales motores, y todo ello, por supuesto, contando con la fundamental pista de despegue y campo de operaciones que fue, desde 1941, La Codorniz. Y para que el proceso todavía resultase más parecido a su precedente de anteguerra, también la modalidad contó con una colección, ahora bajo el sello de la editorial Taurus, bautizada como El Club de la Sonrisa, que en una treintena larga de títulos sumó a autores extranjeros (Edward Burkes, Carlo Manzoni, Robert Lamoreux, Arthur Conte, G. Martota, etc) los siguientes españoles: Rafael Azcona (que encabezó la colección con su Vida del repelente niño Vicente, y repitió con Los muertos no se tocan, nene), Evaristo Acevedo (Los ancianitos son una lata), Tono (Conchito), Noel Clarasó (Historia de una familia histérica), Oscar Pin (Los náufragos del Queen Enriqueta), Juan Pablo Ortega (Olimpo, siglo XX), la Baronesa Alberta, seudónimo de la escritora Mercedes Ballesteros (Este mundo) y los ganadores de los Premios Internacionales de Novela Legión de Humor correspondientes a 1955 -Pepe, de Rafael Castellano-,1956 -Lo malo de la guerra es que hace ipum!, de Jorge Llopis- y 1957 -Mi tio Gustavo, que en gloria esté, de Chumy Chúmez. Y en esa colección (que estuvo editándose entre el 55 y el 58) se editaron dos de las novelas de Neville a las que me voy a referir por extenso en esta ocasión: La piedrecita angular y Producciones Garcia S.A.

1. La primera novela de Neville, y probablemente su mejor narración, se reeditó en 1957 en la colección El Club de la Sonrisa, a la que luego se hace referencia. Pero en esta segunda edición no solo había cambiado la portada, debida ahora al humorista Chumy Chumez, sinotambién el texto en buena parte, pues -como ha estudiado Enrique García Fuentes (1990)- «el cotejo de las dos ediciones revela una serie sorprendente de variantes y supresiones que afectan, incluso, a la intención primera de la novela» de modo que, concluye el citado especialista, «la edición del 57 es mucho menos optimista, despreocupada y moderna». 
Neville, pues, se incorpora a un grupo de narradores humorísticos al lado de otros que son nuevos en aquel segundo periodo, como Azcona, Álvaro de la Iglesia, Evaristo Acevedo o el dibujante Antonio Mingote; todos, al fin, estrechamente vinculados con la cabecera de La Codorniz. $\mathrm{Y}$ es que resulta indudable relacionar esta revista, longeva, popular, ya un clásico de nuestro humor literario y gráfico, con la literatura de humor del medio siglo. No en vano fue su fundador y primer director el nombre más señero del teatro humorístico español, después de Jardiel, como vino a ser Mihura, y todos ellos, a su vez, por el camino del guión, o del guión y de la dirección (así Neville) colaboraron asiduamente con el cine.

$\mathrm{Y}$ es el cine, una visión escorzada del mismo, el espectáculo que voy a examinar en primer lugar en la narrativa de Neville.

\section{Producciones García S.A. o el cine como parodia}

Esta paródica visión del cine producido y filmado en España durante la Segunda República (es decir, en el periodo en el que Neville empezaba como guionista y tímido realizador en nuestra entonces incipiente industria cinematográfica ${ }^{2}$ ) se publicó en 1956 y, aparte de la astracanada historieta que la soporta, debe entenderse como una explícita crítica de Neville contra el cine que se venía haciendo en España y del que él, y algunos otros pocos, quería diferenciarse (y a fe que lo logró, pues hoy, con la sanción del tiempo transcurrido, el cine de Neville se revisa y se valora como el de un auténtico cineasta de culto dentro del raquítico cine español del primer franquismo) $)^{3}$.

2. Leemos en la p. 13 de la novela: «Eran aquellos años cuando se declaró el entusiasmo por el cine, la pasión por este arte y la ilusión de hacerse rico con él. España estaba inundada de revistas cinematográficas americanas. Los últimos años del cine mudo habian sido gloriosos gracias a Greta Garbo y a Chaplin, y a la gente joven la había encalabrinado una especie de chacha ultramarina llamada Clara Bow. Para muchos había sido como la quimera del oro, y todo lo que tocase al cine gozaba de un resplandor lleno de promesas». Es el momento de impacto de un arte, de una estética y de unas figuras que están presentes en muchos libros ensayísticos y de creación de esos años (Alberti, Arconada, Ayala...) y que explica que varios autores de entonces -a la cabeza Martínez Sierra y Jardiel,y con Neville también en la nómina- marcharon a la Meca del cine norteamericano con la expresa intención de trasplantar a nuestros pagos lo que alí vieron e hicieron. Como los personajes de la novela, también aquellos jóvenes escritores de los veinte/treinta creían que «Hollywood era todo», o sea, hermosas mujeres y grandes fortunas.

3. En un momento dado (p. 96) se citan dos títulos de dos películas que pertenecerían al «cine histórico» de la época, y que tienen su correlato en el cine que se programa en España en esa década: La reina martir se correspondería con la cinta de George Sydney La reina virgen, de 1953, y La leona de Villalar con la producción de Cifesa -año 51-La leona de Castilla, dirigida por Juan de Orduña. 
Penuria de medios y penuria de ideas son los dos parámetros que definen la jocosa y pintoresca Productora García. Allí no cobra nadie o casi nadie (desde el guionista al cámara o a la secretaría de producción) y en caja no hay más que unas herrumbrosas monedas para hacer un poco de bulto; el celuloide lo tienen tasado y limitado también el tiempo disponible de filmación en un estudio paupérrimo y alquilado (unas cocheras del barrio de Prosperidad). El tal García, Serafín de nombre (la Paramount o la Metro a la española, que entonces eran Orfea, Cifesa o Cea) era un pobre mercero con algún dinerillo ahorrado ${ }^{4}$ y que, de común acuerdo con su mujer Antonia, había decidido emplearlo en hacer una película del género folclórico y de argumento cuasi folletinesco, si no absurdo. Y lo ha puesto en marcha con la concurrencia de un guionista al que se le propone una idea tan tópica como manida (una de aquellas andaluzadas con toreros y gitanas que tanto predicamento tuvieron en una etapa del cine español -Imperio Argentina, Estrellita Castro...). Ese Rafael de la novelita (trasunto del propio Neville, que empezó también en el cine por el cometido de guionista) tiene que mediar entre un desorientado director (Quintanilla) y un ridículo galán de barrio (Roberto) que se cree la clave de la película, y ve cómo se le desplaza del centro de atención, porque a García, como a todos los productores del momento, «el punto de vista artístico le importa un bledo» (p. 16) También la novela se hace eco de cómo el inicial costumbrismo hispano empezaba a ceder frente al glamour de las comedias norteamericanas (es lo que dicen preferir los espectadores del cine de barrio del prólogo de Eloísa está debajo de un almendro).

Como si se tratase de una comedia de Muñoz Seca (que es a lo que más se parece, por momentos, el argumento y las situaciones de la novelita ${ }^{5}$ ) la solución para acabar el engendro de película que se ha propuesto hacer el arruinado García pasa por sumar al proyecto un socio capitalista

Estas referencias, y otra a la actriz italiana Gina Lollobrígida (p. 99), en la culminación de su belleza como actriz en aquellos años cincuenta, cuando era un éxito notable en los cines madrileños películas como La mujer más bella del mundo -estrenada en España el mismo año de edición de la novela- hacen pensar que el cine que se refleja en la novela es el cine franquista, y no el republicano, como sugiere Jesús de Benito (1999), quien piensa que ese desplazamiento a los años republicanos se hizo por evitar posibles obstáculos de la censura.

4. Según especifica la novela, el tal Serafín García había hecho su capitalito con la venta de guantes (p. 80), referencia que Jesús de Benito (1999) cree motivada por el recuerdo del productor americano Samuel Goldwyn, que también se había dedicado al mismo comercio. Podría ser.

5. Cuando García quiere adivinar la comedia que el socio capitalista que se ha buscado dice que es lo que quiere filmar (recuérdese que fueron las comedias de éxito lo primero que interesó al cine, pensando en su rentabilidad económica) y que «era de risa», «García empezó a disparar nombres de 
que, a ser posible, no entienda nada del nuevo arte, un socio que sea un prototipo del paleto con dinero y extremeño además (la gracia está en que un propietario de aquellas tierras se llame precisamente Don Benito, como el pueblo pacense que había pasado a los anales de la literatura de sucesos por un horrendo crimen novelizado por Trigo).

En su sátira, Neville no deja títere con cabeza: somete al angular codornicesco argumentos, productores, guionistas, directores, actores, y por supuesto a los críticos. Aquí hay uno, como no podía ser de otro modo, y además aficionado también a inventar historias cinematográficas que copia de malas historias de cine, sin pudor alguno. Un crítico que se apellida Murga, que es una $i d e m$, se ha contagiado de anglicismos ridículos ${ }^{6}$ $\mathrm{y}$ ofrece un producto de «seguro éxito»: un remedo de la historia conocida como Currito de la Cruz, que un día escribiera Pérez Lugín (primero como novela -1921- y luego como guión de una película que dirigió él mismo en 1925$)^{7}$. Y el público es también señalado como directo culpable de la mediocridad de ese cine, según sentencia el guionista Rafael Sierra:

Lo que es mucho peor que todas esas organizaciones es el público, que es el que tiene la culpa de todo; si al público no le gustasen todas las estupideces que le gustan, si no patrocinase y cubriera de dinero todo lo que es mezquino, mediocre y ordinario, este pobre hombre de la producción nos permitiría abordar otros temas, no por paladar, sino porque fuesen más comerciales (pp. 29-30).

Neville une, con el engrudo del astracán, el cine con el teatro, o viceversa: quien paga exige, y el rico extremeño solo tiene una manía en la que no ceja: quiere filmar La vida es sueño, y lo quiere por dos razones que ratifican la incuria cultural de ese público que antes señalaba Neville por boca de su personaje-sombra: porque se dice en verso («con estas cosas es

comedias cómicas de Muñoz Seca y de Arniches, para ver si descubría cuál era la obra que tanta gracia había hecho a don Benito. Pero no acertaba con ninguna» (pp. 37-38).

6. El personaje utiliza la voz inglesa scenario para referirse al guión que le entrega al productor, y que finalmente García se propondrá filmar, pese a haberlo rechazado de plano en primera instancia, por aviesa influencia del capital: « «Le he traído un pequeño escenario que he escrito entre horas». Al fin era el guión de otra españolada».

7. Cuando Neville escribió su novela se habían filmado hasta tres versiones de esta historia del niño abandonado en el torno de un convento que acaba siendo torero de fama: en 1925, en 1936 (con dirección de Fernando Delgado) y en 1948 (dirigida por Luis Lucia). Aunque los guionistas fueron distintos, se respetó lo esencial de la historia inicial. Todavía en 1965 Rafael Gil volvió sobre tan añeja historia. Y en 1958 Ignacio $F$. Iquino regresó al mismo asunto en lo que se podría considerar como una quinta adaptación de la historia del novelista galaico-madrileño: El niño de las monjas. 
con lo que se ríe el público», p. 42) y porque, cuando la vio don Benito, le divirtió profundamente («yo me estuve riendo toda la noche», p. 38).

Ya tenemos planteado el conflicto en tan modesta productora: hacer, sin hacer, una película que, presuntamente, fuese la particular versión al celuloide del clásico calderoniano.

Puesta en suerte la acción, Neville la desarrolla en el segundo de los tres capítulos de su novelita: un día en pleno rodaje en el que se trata de rodar una comida de gala con la sociedad de alto copete, o lo que es lo mismo, una secuencia en la que hay que dirigir a una barahúnda de extras hambrientos y con escasa conciencia de que están siendo grabados para la posteridad. Y en esta película, detrás de la que hay un exiguo, un ridículo, un inexistente presupuesto, el director está más para resolver cuestiones de inmediata intendencia que para sacar la mejor vena artística de unos actores espontáneos y buscones del bocadillo. Cuando solo se dispone de «doscientos metros de película virgen» para una escena, no cabe la toma falsa. A lo que asistimos no es al rodaje de una secuencia sino al accidentado ensayo del rodaje de una secuencia.

En el cochambroso estudio en el que trabaja el productor García y el director Quintanilla nada ni nadie funcionan a derechas. Neville recrea una viñeta que pudiera haberse publicado en La Codorniz ${ }^{8}$ : unos hambrientos invitados comiendo sopa, una escena «del gran mundo», trasplantada con fórceps al cortijo de la andaluzada ${ }^{9}$, que se torna, de pronto, en un improvisado galimatías en verso como si fuese una escena de La vida es sueño pasada por el non sense del cine cómico mudo. La mezcla chirriante de géneros, sobre todo cuando la presencia del adinerado y paleto extremeño obliga a disimular la grabación con los versos que cada cual recuerda, como si se estuviese realmente filmando el sacrosanto texto calderoniano, nos lleva a una imagen entre ramoniana y solanesca, que a Neville le había encantado en el comienzo de su carrera cinematográfica: los extras acumulados en torno de la mesa y ante sus humeantes platos de sopa «tienen todo el aspecto de la cola del aceite en Carnaval» (p. 57). La cámara sobre un travelling que no es tal, sino una antigua «jardinera» para desguace,

8. De hecho esta novelita se adelantó, como obra teatral nunca representada, bajo el título Producciones Mínguez, en dos entregas de La Codorniz (núms. 57 y 58, de 1942). Castalia tiene en preparación una reedición de Producciones García S.A. con introducción y notas de María Ángeles RodríguezSánchez.

9. Quintanilla hace mezclas tan arriesgadas solo pensando en la rentable exhibición de la película: «Yo no hagocine para minorías, ni para snobs, sino para las masas, para el público de los domingos» (p. 56). 
desplazándose sobre el chasis de un coche de niño; el sonido captado por un ruidoso artefacto encerrado en una generosa cesta de la compra; los extras que se desplazan como un solo hombre hacia donde creen que están los bocadillos de jamón...

Neville, al hilo de su irrisoria situación, tira puyas contra el cine de su tiempo. Por ejemplo, las manipulación que se producía en los doblajes de las películas extranjeras ${ }^{10}$; las precarias condiciones de las filmaciones... Quien describe con tanta ligereza y frescura un rodaje por dentro, enlazando una chocante situación con un chiste verbal, con una réplica afortunada, con un brochazo casi esperpéntico" ${ }^{11}$ es que conocía el paño a la perfección, es que estaba dando noticia de lo que había vivido y presenciado tantas veces durante los veinte años anteriores como cineasta. Después de ensayar, con todo cuidado y prudencia, se filma. El pasaje hubiese sido de antología de haberse producido en el cine de humor de aquellos años cincuenta. Nos quedó registrado gracias al verbo de Neville en este espléndido homenaje al cine cutre de la España cutre, en la que el polimorfo autor madrileño hacía de liberal bon vivant:

Los extras se sentaron a la mesa como es debido y la Princesa y el Gran Duque se instalaron en la cabecera. El travelling hizo su aparición adelantando hacia la mesa. El coche de niño apenas temblaba y el operador llevaba unos patines en los pies, y el todo era empujado por don Florencio con un tacto exquisito.

Desde que se había pronunciado la palabra «silencio», el ruido había sido ensordecedor, y a él contribuían el aparato sonoro, el carrito y los patines, y entre ese estruendo se oían gemas del diálogo, que en esos momentos adquiría un grado de gran naturalidad. La Princesa, al ver llegar al camarero, le había dado la mano diciéndole:

-¿Qué tal, Enriquito?

El camarero, que estaba muybien educado, contestó:

-Muy bien. ¿Y en casa?

Y la Princesa, en un delirio democrático, contestó:

-Chanchi. Me alegro de verle.

10. Refiriéndose a una actriz que procede del doblaje, alguien objeta que «cambia el diálogo todo el tiempo. Dice que, como está acostumbrada a doblar películas, tiene que hablar como en los doblajes» (p. 53).

11. Cuando la figurante que hace de Princesa debe aparecer en pantalla tirando de unos esbeltos y elegantes «galgos rusos», lo que realmente se ha encontrado en el último momento ha sido un ejemplar de can «que pertenecía a esa raza que va debajo de los carros de los traperos, y que además venía mordiendo un pedazo de periódico lleno de grasa» (p. 64). El efecto, descrito e imaginado en la proyección, resultaría fulminante. 
El camarero, ya lanzado y viendo que era su oportunidad, siguió la conversación:

- Y yo. Por usted no pasan los años.

Sin embargo, otros trozos de conversación llegaban de la escena. El Gran Duque Pablo tiraba de la manga al camarero diciendo:

-Yo quiero más sopa.

Y otro extra se quejaba:

-A mi no me han tocado fideos.

De pronto se oyó un enorme sorbetón de alguien que no había oído la orden de no empezar a comer en esa escena y Quintanilla dio la parada.

-¡Stop! (pp. 65-66).

En esas aparece inesperadamente don Benito; todo se trastrueca; el astracán está servido: versos inconexos y añejos servidos en trajes del «gran mundo». Neville, que no había hecho un teatro tan descoyuntado como el de Jardiel, se acerca ahora a aquella estética en la secuencia que sigue, en su novela, hasta que acaba el segundo capítulo. Y conste que Jardiel había embutido en un texto teatral los entresijos y las tomas falsas de una filmación vista por dentro: había sido en la comedia de $1941 \mathrm{El}$ amor solo dura 2000 metros ¿Quiso Neville avanzar por el mismo camino? Hasta hay su tierna historia de amor, entre el guionista y la secretaria, como la había en la comedia de resaca hollywodense de Jardiel. Pero volvamos a la estrambótica situación que se avecina. Le podríamos poner el mismo título que se le ocurre a Quintanilla: «Segismundo, que ya se ha despertado, toma sopa» (p. 67), y, desde esa improvisación, hasta parece concederle a su ricacho de Badajoz una miaja de ocurrencia: "Ya comprendo, y luego un sopor y se duerme» (porque a don Benito lo que más le había interesado de La vida es sueño había sido el predicado nominal de la oración). Es un final en punta, hilarante y patético al mismo tiempo: por un lado el estupor (la niña «hidrofóbica» agarrada al brazo turgente de la princesa, sin soltarlo de sus dientes) y por otro la desolación (el operador, inadvertido del simulacro, había gastado en aquella atrocidad los últimos cien metros de película). El desenlace de la cinta y de la novela en el siguiente y último capítulo.

Allí es donde, en los restos de una oficina destartalada en la que el embargo intenta entrar a saco, Neville va a dar rienda suelta a sus críticas del cine del que su filmografía quiso ser una alternativa a la altura del medio siglo. La aventura cinematográfica de García había acabado - parececon el más fulminante de los fracasos, y por tanto el espontáneo productor cinematográfico «comprendió que eso del cine no era para él y anunció su retirada y su vuelta a la mercería y a la venta de guantes» (p. 80). 
¿Cuál es el cine que defiende Neville? El que responde al que sugiere el guión-tipo de Rafael y por el que, de momento, ninguna productora se ha interesado: la película moderna, alejada equidistantemente de las emulaciones americanas como de los tópicos estereotipados de la españolada republicana y de los primeros años del franquismo ${ }^{12}$. Una película cuyos personajes «no son nada típicos, no se ponen nunca trajes regionales; son personas como esas que ves en las calles de las ciudades, y que les ocurren cosas iguales a las que les ocurren a la gente, pero que las toman de una manera normal y reaccionan de un modo menos primitivo que los gitanos y los paletos y las mozas y los mozos, y los burros, y los toros, y demás actores de las producciones al uso» (p. 83). Un cine-como el que llegó a filmar Neville: La vida en un hilo como ejemplo paradigma- que bien poco se parece al dominante y rechazado por el guionista Rafael, tras el que vemos la aquiescencia del conde de Berlanga de Duero, al tiempo que refería sus preferencias en materia de cine:

Me carga el folklore, los mozos, las mozas, sus trajes, sus dichos y sus costumbres, que me parece todo ello asqueroso y que siento mucho que sean mis compatriotas, que no creo en ninguna de esas palabras altisonantes con que quieren ponerlos como ejemplo, y que la prueba de que son unos monstruos es que en este país nos pasamos la vida peleándonos y sin saludarnos los unos a los otros, nos llevamos como perros y gatos y el de cada provincia no puede aguantar al de la provincia vecina. A mí me interesa otro tipo de gente más ciudadana, más de gran capital; con problemas de hoy, pero también con reacciones de hoy; con una buena educación; que no crean que son muy graciosos y muy francos porque al pan le llama pan y al vino vino, que es un pretexto para insultar al público (p.84).

Neville se extiende en criticar un tipo de cine que, pese a tener practicantes y seguidores en aquellos años, lo consideraba como una materia deleznable («podredumbre», «cieno»). El cine basado en los valores eternos del terruño, dice Neville, no es sino el cine de «unos guarros espantosos», «y nosotros nos empeñamos en que éstos sean nuestros personajes cinematográficos, en presentarlos como a lo más genuino y admirable del pueblo español». La película que Rafael había escrito, forzado por las circunstancias, para Producciones García, era la de los «catetos asquientos»,

12. A ese momento estético e ideológico, más que al de los años republicanos (deacuerdo con lo indicado en la nota 3, apuntarían estas observaciones de Quintanilla acerca del interés de un cine que siente respeto «por las virtudes acrisoladas de esta raza de monjes y de guerreros, de santos y de mártires» (p. 84). 
y estaba muy lejos de un cine «sociológicamente europeo» por el que cineastas como Neville luchaban desde detrás de una cámara. A la altura del año en que se edita esta novela (1956) ya se habían estrenado títulos significativos de este cineasta, aunque todavía quedaban por llegar dos de los mejores: El baile y Mi calle, y un tercero, La ironía del dinero, al que luego habré de referirme.

Neville, a través del cambio de impresiones de dos profesionales del medio (las dos facetas que él supo desempeñar: el escritor de historias y el director de sus filmaciones), diagnostica el presente y el futuro del cine de su tiempo: lo que entonces gustaba popularmente y la alternativa de un cine menos mostrenco, aunque probablemente peor admitido. Se habla, incluso, de un cine para espectadores de ciudad y otro para los de pueblo, ya que «España es un país muy difícil porque hay demasiada diferencia entre los públicos de las diferentes regiones» (p. 87) ${ }^{13}$.

Lo esencial de la parodia y de la crítica de ese tipo de cine y de la debilidad estructural de la industria cinematográfica hispana está hecho cuando llegamos a este punto de la novela. Queda la escena-cien por cien teatral- del enamoramiento del guionista y de la secretaria, de Rafael y Carmela. Una idílica secuencia entre una pareja en ciernes, a la orilla de un charquito de agua, como un imaginado río, y un florero salvado del naufragio, en medio de una habitación vacía que se contrapuntea con un arruinado productor asediado por sus acreedores. Y, para demostración de lo que páginas atrás se ha criticado, la sorpresa trufada de ironía como

13. Y Neville aprovecha la ocasión para (recordando que la historia de su relato está ubicada en año 32) criticar la República, los fallos de la República, desde unos años franquistas en los que era norma establecida difundir una imagen negra del mismo periodo: «Estábamos tan ricamente con la monarquía, y hasta que hemos proclamado la república no hemos parado, y ahora ya estamos otra vez. todos enfadados [...] la República ha sido, si quieres, una tontería. Nos ha fallado lo que falla siempre en España, que son los hombres políticos». Y, rizando el rizo, hace un guiño de censura al sistema dictatorial desde dentro de ese sistema: «Si hubiera surgido entre todos tus preclaros [le dice Rafael a Quintanilla, aludiendo a esos personajes de la cintas bien aceptadas por los espectadores del terruño] uno que lo fuera verdaderamente, la República no sería lo que es». A lo que responde el director: «Entonces iríamos a una dictadura otra vez, para salir de ella con las manos en la cabeza».Claro que todo parece matizarse, en sentido contrario, pro-franquista, en los párrafos siguientes de la misma conversación: «Aún queda la esperanza de que un día surja un político con energía, con autoridad y con el profundo sentido de la tolerancia imprescindibles para gobernar un país tan fraccionado espiritualmente como éste», arbitra el liberal guionista, desiderata que repite ante la rotunda afirmación de Quintanilla («Aquí lo que pasa es que nunca hay unidad») en unos términos de «idealidad moral» verdaderamente utópicos aún en la España, y la Europa, de 1932 y de 1956: «Un país no puede estar unido más que por medio de un compromiso moral, por una especie de concordato en el que cada bando sacrifique sus postulados más extremos para que el otro pueda sentirse satisfecho, $\mathrm{y}$, sobre todo, por un árbitro que impida eso que decian las chulasen los chotis, y es el que «nadie quiera propasarse»»» (pp. 87-88). 
remate: la desastrosa película que había apartado al señor García de las lides cinematográficas ha sido un éxito al exhibirse en las "atrasadas» tierras extremeñas, $y$, lo que resulta más cómico todavía, la interpretación crítica que se hace de la película por el sesudo especialista Murga. Después de que el lector haya pasado por la astracanada del rodaje descrito en el segundo capítulo, no puede por menos que carcajearse ante la manera de interpretar lo que no era sino los gajes de una filmación envuelta en la pobretería y el desconcierto, lo que, sumado, da -paradójicamente- «una obra de imaginación»:

Tal sucede con una escena que representa una comida en un palacio, en la que los personajes se sientan vestidos con trajes de hoy y de repente aparecen tocados con trajes del siglo Xvil. ¿Se puede pedir más al cine español que este toque freudiano?[...] Se ve que el director ha querido dar a entender que los personajes sugestionados por el ambiente, se veían los unos a los otros vestidos así. La escena no puede ser más romántica, y su hechizo es tal que no se alcanzan a captar los bellos versos que recitan los actores, tan absorto como está uno con los trajes y el simbolismo de la escena (p. 106).

Y la boba sagacidad interpretativa del crítico llega al máximo cuando le da la vuelta «simbólica» al inaguantable ruido del armatoste sonoro de don Fulgencio:

Lo más impresionante y lo más original de la película es el leit motiv del viento. Durante toda ella se oye el silbido del viento que se estrella junto a los personajes: es la simbolización del pecado queriendo morder a las gentes de bien. Silba Eolo en diferentes tonos y a veces, como en la escena ya mencionada de la comida, se oye la tormenta, se siente cómo los truenos se aproximan...Estos son los efectos más bellos del film (p. 107).

Cuando la estulticia se viste de pedantería es capaz de producir desbarres interpretativos como el precedente.

El éxito, contra todo pronóstico, de la incoherente película le da la victoria al cine que el guionista Rafael denostaba. El «espontáneo productor» García vuelve a las andadas. Hay nuevo dinero para hacer dislates que gustan a un público nada preparado, nada exigente. Neville no tuvo buena suerte con los productores (en el personaje de García se venga de una clase que le resultó hostil) y tuvo que producir muchas veces sus propias películas. En correlación, García dispara contra sus enemigos naturales, «más o menos solapados»: «el artista, el escritor, el director» (lo que, al unísono, fue tantas veces Neville). Definitivamente productoras como la que García S.A. Cinematografía representa vienen a impedir las pretensiones de 
renovación de las películas españolas, porque no es bueno, ni viable, ni prudente empeñarse en hacer un cine «por encima del alcance del público que paga, de ese público que nos ha dado anoche el triunfo» (p.109). Neville parece sentar esa premisa preocupante (que en cierto modo podría extenderse al teatro y hasta los toros): son los productores-empresarios los que deben poner los filtros necesarios para que el arte no suba el anclado nivel de la mediocridad: «ir cortando, poco a poco, todos esos vuelos de la imaginación del artista hasta dejar la obra al alcance de los pueblos donde va a ser exhibida» (p.109). Por boca de su peculiar productor, Neville llega a una ecuación patética en el fondo: «faltan ideas, imaginación y arte, ipero precisamente por eso se ha producido el triunfo! (p. 109). Ante tal situación, a Neville y a su «socias» no le cabe otra solución que el retiro horaciano hasta tiempos mejores para la inteligencia.

Todavía queda tiempo para crear una situación codornicesca: recuperar el guión que antes se había rechazado por malo y que ahora se reputa de obra maestra. Y un chiste que no desdeñaría ser publicado en $\mathrm{LaCo}$ dorniz de aquel tiempo: se piensa que el guión perdido se lo ha llevado el trapero; hay que localizarlo urgentemente: «¿Dónde vive el trapero?.--En el Hotel Ritz» (p.112). Inversiones chocantes como esas estaban en Jardiel, y tambiénen el primer Mihura (y estoy pensando en títulos como $\mathrm{Ni}$ pobre ni rico, sino todo lo contrario).

\section{Toros y teatro: dos espectáculos desenfocados en La piedrecita angular}

2.1. Neville fue un buen aficionado a los toros y esa afición la llevó a los relatos y al cine, aunque es un asunto ausente en su teatro ${ }^{14}$; pero lo hizo desde una postura crítica más que elogiosa, incidiendo sobre lo que en la Fiesta había de excesos, de crueldad, de pésimo gusto, incluso. Una de sus películas más olvidadas es la titulada El traje de luces, de 1940, y uno de sus mejores cuentos es «Torerito soberbio», y en el marco de una sesión taurina se desenvuelve uno de los apólogos mostrados en la injustamente minusvalorada película de Neville La ironia del dinero.

En otro relato breve, «Gloria taurina» (incluido en el volumen del 55 Torito Bravo Barcelona, José Janés, pp. 151-153) se hace un primer esbozo de un personaje colateral del universo taurino, uno de sus antihéroes,

14. Algunos de los artículos-relatos publicados en la revista Gutiérrez tienen a toros y toreros como protagonistas, $y$ es sabido que esta afición taurina surgió tras ver una faena del diestro Juan Belmonte. 
los que el narrador describe como «estos vestales supremos de la gloria taurina»: los espontáneos (mercenarios) aficionados que, entrando gratis al coso durante la lidia del último toro, se comprometen a izar sobre sus hombros a los diestros más o menos triunfadores y portearlos calle adelante hasta no se sabe bien dónde ni cuándo. Son las pobres plataformas humanas de la gloria que dan los cuernos de los toros bravos. Los «portatoreros», oficio que Neville acuña en el planeta taurino. Uno de ellos es el protagonista de una peculiar «novela barojiana» de humor de Neville (un desarrapado que podría haber prohijado don Pío, por ejemplo) en la que también recorreremos el otro espectáculo de masas, el teatro: La piedrecita angular, la segunda presencia de Neville en la colección El Club de la Sonrisa de Taurus (1957).

El bueno de Miguel es un hombrecillo de buen corazón, de corazón casi infantil, que dormita a la sombra de una estatua de otro luchador de la vida, como él, la del soldado Eloy Gonzalo, héroe de Filipinas, en el mismo umbral del Rastro. Neville en esta novela rinde doble homenaje a Madrid y a su maestro Ramón porque el buscavidas Miguel se pasea por los lugares más populares de la capital (desde la Ribera de Curtidores a la plaza de las Ventas y la carretera de Aragón) y además se mueve perfectamente en el ámbito peculiar del Rastro, ese espacio que elevó a categoría Gómez de la Serna en uno de sus últimos libros de aprendizaje, en 1914, El Rastro, como el mundo del cine y el de los toros también podrían haber sido incentivados por otras dos novelas ramonianas: Cinelandia (1924) y El torero Caracho (1927), respectivamente. Miguel quiere proteger a dos muchachas adolescentes para hacer de ellas dos señoritas de provecho: una, bailarina de fama; otra, profesional de prestigio en algún ramo del peritaje. Pero los empeños y los sueños son, por lo general, caros, y Miguelito necesita portar toreros triunfadores por la calle de Alcalá arriba, sin contar con que ese oficio está mas sujeto a las eventualidades que el de jornalero del campo, pues no solo depende de la bonanza meteorológica sino también del acierto de los diestros ante el exigente respetable. Y en los «sanisidros» de ese año elnuevo portador de toreros no parece tener la suerte de cara: cuando no llueve sobre la Monumental los toreros están para tirarles almohadillas y lo que se ponga a mano. Solo a uno, y de los peores, logró Miguel arrebatarlo sobre sus entrenados hombros... y es que la (mala) suerte aprieta, pero nunca hasta ahogar.

De la mano de tan peculiar apéndice de la fiesta brava entramos, por la puerta de caballos, en el coso madrileño y presenciamos, con los ojos neófitos de Miguel, un espectáculo taurino que Neville parece pintar con los brochazos de Solana, pero desde la mirada cínicamente desvirtuadora de una insensible matrona que pretende calmar y distraer a su llorón in- 
fante con tan sangriento y violento espectáculo (y esto está escrito cuando la normativa del Ministerio de Gobernación prohibía la asistencia a las corridas de toros de menores de catorce años). El párrafo que sigue nos deja tan perplejos como al testigo Miguel: la madre intentaba sofocar los llantos de la niña $\mathrm{y} .$.

explicaba los momentos puntuales de la fiesta para que la niña los contemplase [...] Mira niña - decía- jahora va a matar al caballito! Y la niña volvía la cabeza hacia el ruedo y veía cómo el toro arremetía contra el caballo y le introducía un cuerno en la tripa. El angelito sonreía complacido, pero luego, cuando el toro se alejaba del caballo, volvía a llorar. Y entonces la madre le decía, haciéndola bailar sobre las rodillas: - Mira, mira, ¡Ya sale sangre!, ¡ya sale sangre! [...] -Mira, mira - decía la madre en otro momento-, ya han cogido al torerito. Y en efecto,habia un torerito flotante durante unos segundos en el aire como un pelele, y una vez en la arena era de nuevo acometido por la fiera, hasta que ya por fin la asistencia se lo llevaba a la enfermería. Entonces la madre volvía otra vez a entonar su canción de cuna: ¡Ya han matado al torerito! ¡Ya lo han matado! ¡Ya to han matadito! (pp. 55-56).

Una visión tan sádica de la fiesta, presentada en forma de juego inocente pero de humor corrosivo, se intensifica en el angular referido al bárbaro comportamiento del público, «esa tremenda manifestación de cobardía que es el espectador de toros que insulta al artista» (p. 57) y que contrasta con el imaginario monólogo de un toro cobardón que querría quitarse el sambenito de su enemistad con el hombre, con el torero, esos animales que preferirían ser

útiles a la Humanidad, útiles a la sociedad» antes que objetos de lidia en un circo romano, toros que quisieran ser tan nobles, y algo menos tontos, que los caballos, en general, y que los caballos de pica en particular («Nosotros no queremos matar al noble bruto, no queremos matar al caballo, ni tenemos por qué darle cornadas a un hombre que no nos ha hecho nada hasta ahora y que va vestido de una manera tan bonita. Nosotros lo que queremos ser es..., como decíamos, unos toros domésticos, unos toros alegres, a los que podían poner unas campanillas y nos podían mandar a recados y seríamos un avío en las fincas y en los cortijos, e incluso en las ciudades (p. 65).

No estamos muy lejos de lo planteado en el cuento «Torito bravo» ni en la película El último caballo. En aqué $1^{15}$ el pobre y tímido Juanillo

15. El cuento encabezaba y daba título a una colección de relatos de 1955 
siente un profundo afecto, una tierna camaradería por los toros que cuida en el cortijo donde trabaja, y en especial por el nombrado Pocapena, al que un día logra indultar en una plaza de toros y asume la responsabilidad de lograrle al animal el feliz retiro de semental en la misma dehesa en la que se había criado, aunque para ello tenga que aprender a torear, a alcanzar el pedestal de la fama, pero también a recibir (en una hermosa y patética secuencia final) la muerte por herida de asta de toro. En ésta (que se estrenó en 1950: tal vez la primera comedia neorrealista española en el tiempo) un soldado de caballería se empeña en librar a su caballo de ser destripado en una plaza de toros y finalmente troceado y vendido en la carnicería, y para ello tiene que luchar contra mil inconvenientes como un nuevo quijote urbano. Pero también podemos encontrar clarísimos ecos de esta narración (yo diría que evidentes transferencias) en una de las historias enlazadas en la película La ironía del dinero (con guión del mismo Neville, esta película se filmó en el 55 pero no fue estrenada hasta el 59). Un forzado a torero de ocasión, para salir de pobre y comprar el puñado de tierra en la que trabaja de sol a sol (y que se hace llamar en los carteles «El hambrientito de Cuenca») prueba fortuna una tarde en las Ventas y solo obtiene, con un terrible revolcón, el comprobante de que jamás podrá ser torero; pero el destino es bondadoso con el esforzado joven (magistralmente encarnado por Antonio Casal) y hace llegar a sus manos una cartera atestada de dinero para lograr lo que quería. Durante la lidia del toro que le toca en suerte Neville traspasa a las imágenes el párrafo de la madre animando a la menor con la agresividad del festejo, que antes he trascrito, y -segundo enlace con La piedrecita angular- el torero triunfador de la tarde ve alejarse la posibilidad de apropiarse del dinero encontrado cuando dos porteadores de toreros, previamente pagados, se empeñan contra su deseo en sacarlos a hombros de la plaza y llevarlo así, jaleándolo, por toda la calle de Alcalá.

2.2. El segundo oficio que afronta el buscavidas de Miguel es el de regidor de una compañía teatral de provincias. Y ya tenemos el escorzo del teatro metido en la narrativa humorística de Neville, y contando con su conocimiento puntual del asunto, como lo tenía de los rodajes cinematográficos en la novelita anterior.

¿Cómo era una compañía de cómicos de medio pelo por dentro? La perfila Neville en el segundo capítulo de La piedrecita angular: el voluntarioso empresario que anima a unos melancólicos y olvidados actores en las tertulias pobretonas de café a salir a provincias, en condiciones ínfimas, con un repertorio adaptado a sus escasos medios técnicos y cualidades profesionales no menos escasas, y en la que no debe faltar progra- 
mación tan socorrida como el Tenorio, algún juguete cómico o alguna comedia de los Quintero y, por si acaso, la comedia de salón firmada por Don Jacinto $^{16}$. Una compañía que viaje en los incómodos asientos de madera «de un vagón de tercera» (aunque se ganen la comprensiva condescendencia del revisor de turno, dejándoles salir y entrar en la estación capitalina asomados a las ventanillas de los departamentos de primera) y que, como en la artesanal Producciones García S.A., necesiten un novel y pésimo dramaturgo con ansias de gloria para sufragar los insoslayables gastos de intendencia hasta conseguir la primera taquilla con mediano rendimiento.

Así, en un curioso antecedente del notable texto de Fernán Gómez Viaje a ninguna parte, Neville nos presenta un elenco formado por el primer actor, «un hombre amargado y triste, porque las compañías más importantes se habían olvidado de él o no querían contratarle porque hacía «sombra», según afirmaba» (p. 73); por la dama joven, que lo era «más por el título que por la edad», ya que «era dama joven porque había sido dama joven los últimos cuarenta y cinco años y ya no era cosa de cambiar de categoría» (p.73); por la meritoria, más hermosa de carnes que llena de méritos actorales, con el apéndice de su mamá y proclive, por tanto, a una larga retahíla de situaciones cómicas; y con ellos, un escaso resto procedente «de la erosión del teatro en España, miembros perdidos de esa gran familia desbandada por la crueldad con que los empresarios de los locales de provincias y pueblos han perseguido a las gentes del teatro no dejándoles actuar los sábados y los domingos para poder poner una película del Oeste ${ }^{17} \gg$ (pp.75-76). Neville no ahorra situaciones chocantes, cómicas, incluso patéticas para cantar las heroicas penurias de los «cómicos de la legua» como éstos entre los que se ha enrolado, para hacer suerte, el bueno de Miguelito y una de sus protegidas, la bailarina. Cuando no es el cine de moda (más barata su exhibición, más rentables sus recaudaciones) es la compañía de folklore la que le gana por la mano a la compañía de teatro serio, porque ante estrellas del tablado como La Taranta, La Pincho y los tres maricas de Montoya, «ante eso, no había nada que hacer».

16. Sin olvidar la muy prestigiosa obra de Calderón La vida es sueño, esa obra, la única, que había visto en provincias don Benito y que le había convertido de la noche a la mañana en un apasionado de la producción cinematográfica.

17. Las tensiones entre cine y teatro que la referencia supone se constatan unos párrafos adelante, cuando la compañía de cómicos encuentra su primer escollo en Albacete porque la empresa propietaria del teatro no cedía ante la buena acogida de una película de tal género por la que «la gente llenaba el coliseo, y la compañía del señor Mijas tuvo que buscar otro lugar donde exponer su arte y su talento a la mayor gloria del teatro español» (p. 80) 
Claro que la primicia que ofrece representar la compañía de Mijas, la obra de un novel que corre con los primeros gastos de los cómicos bajo la promesa de verse estrenado por ellos, es un dramón de los que se patean hasta echar el teatro abajo. Y buena parte de ese capítulo tercero se centra en la accidentada representación de Las murallas de Jerusalén en el teatrito del Casino de Labradores de Molinos de los Llanos (como una buena porción de la novelita anterior se centraba en la filmación de la escena de la comida de gala en el cortijo). Una representación que empieza por reclutar un público zafio o indiferente que paga en especies comestibles y que se carcajea y vocifera ante una escena llena de rimbombante dramatismo, de sonoros y artificiales versos, que se ha de escenificar a telón accidentalmente desprendido, y con los actores en cuclillas para que se les pueda ver en tan exiguo espacio: «y cuando los protagonistas tienen que hacer el movimiento de ir el uno hacia el otro y darse un beso, se desplomaron pesadamente sobre sus posaderas y la escena tuvo un final que jamás había tenido en vida de los gloriosos hermanos Quintero» (p. 99).

Volvemos a idear situaciones de una comicidad que raya lo hilarante, que es deudora de las grosuras astracanescas a las que se les ha pasado la lima por ciertas aristas y excesos. La escenificación de tan tremendo bodrio del iluso dramaturgo novel acaba con la retirada vergonzante de los cómicos subidos en lentas y destartaladas carretas camino de la estación de ferrocarril más próxima, como si fuesen poco menos que los integrantes de la compañía de Angulo el Malo cuando, de un concejo a otro, se los topó don Quijote (II, 11) en la mitad del camino, de un camino manchego como ahora.

Pero las huestes de Mijas no han acabado todavía sus aventuras -o malaventuras- andantes. Una nueva estampa, ahora con mayor presencia e implicación de Miguel y la muchacha a la que desea ayudar, se abre paso en el tercero y último capítulo de La piedrecita angular: el encuentro de los cómicos con los ingenieros americanos que trabajan en la «cooperación económica con España», fruto de los pactos del 53. Ahora estos americanos ricos, poderosos y benefactores no pasan de largo, como en la coetánea película de Mihura-Berlanga Bienvenido, Mr. Marshall. Ahora la maltrecha y deprimida compañía de actores recupera fuerzas en el campamento de los técnicos y obreros del oleoducto Tarifa-Zaragoza y para corresponder a la hospitalidad recibida les ofrecen lo único que saben hacer a medias, el arte de Talía, aunque de nuevo no hayan topado con el público que se merecen. Claro que, a cambio, es la ocasión de que Miguelito encuentre algo que enderece su mala fortuna, encuentre su «piedrecita»-si no su «piedra»- angular, la que encarrile definitivamente su vida en las autopistas de la holgura económica. Así pues, en esta última parte de la 
novela Neville bifurca la acción de la misma: por un lado sigue con los aspectos grotescos de las funciones teatrales improvisadas; por otro, coloca a su idealista e ingenuo personaje (otro quijote de su larga galería) en el centro de una anécdota que le hará creer que ha encontrado el talismán de la suerte. Despacharé rápidamente esta última, que interesa mucho menos para lo que aquí se persigue, $y$, además, es una manera forzada de rematar el relato, por parte de Neville, y hasta de justificar su propio título. Miguel, cuando regresa ocasionalmente al pueblo manchego en el que la compañía ha sido despreciada, casi vejada, es recibido a pedradas, pero resulta que los cantos rodados con que ha sido obsequiado parece que tienen un inusitado interés mineralógico para el ingeniero yanqui y se truecan en una considerable cantidad de dinero para quien, desde ese momento, se dedica a ir periódicamente al pueblo, dejarse apedrear y llenarse sombrero y bolsillos de tan rentables pedruscos, de tan particulares «piedras angulares» de su fortuna. La piedra que le produjo pequeña descalabradura fue su primera «piedrecita angular».

Vayamos al escorzo teatral, ahora en campamento americano. Neville, que había pasado años felices y había aprendido mucho de cine en tierras hollywoodienses, parece ahora darnos la contrapartida con una pintura algo sarcástica de los americanos que colonizaban media Europa en los años de la Guerra Fría, y sobre todo colonizaban España en forma de interesada ayuda: una función «en homenaje a la amistad hispanoamericana» (algo de eso es lo que se proponía el alcalde y todo el pueblo de Villar del Río en la ya clásica cinta de Berlanga).

El propósito es sencillo y digno: «se representaría Rosas de otoño, y, con el producto de la módica entrada, se costearía el viaje de regreso de la compañía hasta Madrid» (p. 103). Pero los propósitos iniciales se ven truncados porque tampoco el público ante el que ahora van a representar gusta de un teatro distinto: los americanos querían revista, teatro con música y erotismo, algo así como un music-hall trasplantado a las secas tierras de la Mancha, y hasta se propone una excentricidad tan transgresora e inadmisible en el casto y serio teatro franquista como era un "streptease», una exigencia del respetable americano (lo extranjero atentando contra la pureza de las costumbres españolas). Satisfacer esa exigencia, sin menoscabar la imagen y la moral de las dos artistas jóvenes del elenco, es el encaje de bolillos, el reto que tiene entre manos la compañía de Mijas. Por fin la responsabilidad caerá en la ingenua dama joven, que ha de inventarse lo preciso para «componer un streptease católico y castellano» (p. 106). Ni qué decir tiene que sobre este escollo Neville se recrea, y como si de una escena de alguna de sus películas se tratara, la ingenua «damita con mamá» ejecuta su casto desvestimiento ante unos alegres yanquis que, 
por fin, dedican a aquellos cómicos los aplausos que han ido a buscar por los caminos de media España. Y, llegado el momento cumbre, la picarona muchacha, vigilada de cerca por su madre, sale a escena con más ropa que capas tiene una cebolla. Pero lo que asegure la firmeza de la amistad hispano-americana será el arte danzarino de Mariquilla, pues ante sus ágiles y elegantes pasos de baile, «una brisa optimista recorría todos los pechos de aquellos hombres que llevaban día tras día, meses, recorriendo la árida corteza de España, empalmando un tubo con otro» (p. 120). Aquella actuación será la verdadera piedra angular para la nueva artista: de aquel escenario improvisado marchará a la gloria de muchos teatros de postín. Por fin en la compañía de Mijas había nacido una estrella. A cambio, el bueno de Miguel (quijote que renuncia a su Dulcinea ${ }^{18}$ ) volverá a su antigua pobreza, regresará al Rastro -de donde había surgido- a soñar con la mejor piedra angular en la que apoyar su frente, mientras echa una siestecilla descansando la sien en el plinto de piedra del soldado Cascorro, otro soñador de utopías desde el umbral del Rastro.

Pero el acercamiento al teatro desde la prosa no lo agota Neville en esta novelita. A él se refiere en otro episodio del relato La niña de la calle del Arenal y en algún codornicesco episodio de su excelente libro $L a$ familia Minguez ${ }^{19}$ (libro que merecería una reedición y un estudio monográfico). Las dos damas y amigas -empezando por el segundo caso- de esta familia burguesa venida a menos en el Madrid del hambre y las estrecheces de los cuarenta van un día a un teatro de la capital. No saben muy bien lo que van a ver, están acostumbradas a presenciar un teatro rancio, archisabido y archiconocido, ese teatro contra el que rompió lanzas Jardiel y su grupo, ese grupo en el que había hecho sus primeras armas también Neville (el estreno de Margarita y los hombres se fija en 1934, aunque sin pena ni gloria) y en el que la prelatura la heredó Mihura. Precisamente la comedia -que les resulta insólita-para la que han adquirido sus localidades doña Encarnación y doña Purificación fue la que Mihura escribió en colaboración con Tono y que vino a ser su segundo asomo a los escenarios, ya que ningún empresario se atrevía aún a programar sus inmarcesibles Tres sombreros de copa. El 17 de diciembre de 1943, y dirigida por Escobar, se estrenaba en el María Guerrero Ni pobre ni rico,

18. Una variante de las relaciones maduros-jóvenes que abundan en el teatro y el cine de $\mathrm{Ne}$ ville, y que no están muy alejadas de una proyección personal.

19. Mihura adelantó buena parte de este libro en una serie de colaboraciones en La Codorniz. La primera edición data de 1946 (Barcelona, José Janés) y una segunda -por donde cito- de 1957, para la editorial madrileña Afrodisio Aguado. 
sino todo lo contrario ${ }^{20}$, algo así como la fórmula de humor de lo absurdo, de lo disparatado, más próxima y posibilista a los «tres sombreros» que entonces podía admitir, y digerir, el público teatral español. Pero no todo el público, pues según cuenta Neville la propuesta de Mihura-Tono superó ampliamente la capacidad de las dos señoras, para las que aquella tarde de domingo decembrino no pudo sermenos que «espantosa». Veamos: las distinguidas espectadoras han tardado unas escenas en darse cuenta de que «no se trataba del tipo de teatro a que tienen afición doña Purificación y doña Encarnación. Allí no había ninguna mocita dicharachera ni ningún ingeniero que quisiera casarse con ella; allí no había tampoco frases profundas como las que anotaba después doña Encarnación en el libro de compra. Aquello parecía como si todos estuviesen $\operatorname{locos}^{21} \gg$ (p. 80). Claro que Neville, hábilmente, se concede en medio de la crítica al teatro viejo, gastado, un autorreconocimiento al lenguaje humorístico codornicesco, del que también participaba el texto de Mihura y Tono, pues señala, con un guiño de complicidad al lector, que «a veces los personajes decían cosas que a ellas no les chocaban porque las reconocían como frases suyas, y lo único que les extrañaba era que hacían reír a las gentes» (p. 80), y es que, en efecto, las expresiones y comportamientos de las señoras de la aristocracia que coinciden en el parque con el conjunto de extravagantes pobres se corresponden con las que Neville pensó para su codornicesca pareja de féminas: «A mí, lo que más me molesta es que se rían de mí, y en esta obra se ríen de mí. -Sí, se rien de usted, Encarnación. -Y se ríen de usted, Purificación» (p. 83) Por ello las bienintencionadas señoras, que se han equivocado al consultar la cartelera de espectáculos de ese día, se sienten como trasplantadas a la escena, expuestas a la risa de un público que sí parece congraciarse con las excentricidades sin lógica de las situaciones teatrales. Un humor nuevo que a ellas las descoloca, las molesta, y sobre todo porque hace reír al propio hijo de una de las señoras: si la sátira de usos y costumbres, que es La familia Minguez, se focaliza desde la mirada inconformista, rebelde en ocasiones, del adolescente Luisito, y desde él medimos el grado de empaquetada ridiculez de los mayores, no ha de

20. La obra se repuso en el madrileño Teatro Martín en los años ochenta y se ha reeditado en el vol. I de la serie Historia y Antología del Teatro Español de Posguerra, Madrid, Fundamentos, 2003 (col. dirigida por V. García Ruiz y G. Torres Nebrera) y en Teatro Completo de Mihura que ha publicado en 2004 Cátedra, al cuidado de Arturo Ramoneda, en la col. Biblioteca Aurea.

21. Por este comentario y otros que luego se hacen, Neville está sintetizando el teatro viejo, contra el que dispara, en modelos de comedia muy próximos a los diseñados por los Quintero (se insiste en la gracia y simpatía de diversos personajes andaluces) y otros autores afines (Serrano Anguita, José de Lucio y el prolífico Torrado) 
extrañar que sea el mismo Luisito el que esté preparado para entender los registros de nuevo humor de aquella comedia, frente a la incapacidad de su madre y de la amiga de ésta: la «carne de su carne, número de su clan, que por la magia del teatro se pasaba con grandes carcajadas al enemigo» (p. 80).

Al hilo de los negativos juicios que le merecen a las dos amigas la obra de Mihura-Tono van surgiendo paralelamente los elogios a otras obras espléndidamente consideradas, y a través de esos comentarios podemos entrever títulos, situaciones, personajes, diálogos de lo que ya debía estar arrumbado y que la penuria teatral de la primera posguerra se empeñaba en apuntalar para que continuase. El teatro por el que doña Purificación y doña Encarnación apuestan es similar al cine comercial defendido por el productor García y el director Quintanilla en Producciones García S.A.. Y por ello no pueden por menos que escandalizarse de la reacción de aquellas damas de la alta sociedad - con las que les gustaría identificarse-en el segundo acto de $\mathrm{Ni}$ pobre ni rico...: es inverosímil de todo punto y razón, dice una, que «esa baronesa y sus amigos se vayan a pasar la tarde con unos mendigos», pues, como subraya la otra, «si fueran a llevarles prendas del ropero, digo yo, un abriguito de esos de lana marrón, se podría comprender; pero irse así, a un desmonte, a merendar con unos pordioseros, no es verosímil» (pp. 82-83).

«A los diecisiete años pretendí hacer teatro entre clase y clase, con mi compañero Pepe Martín. Los dos escribíamos comedias llenas de chistes, que llevábamos, inútilmente, por los teatros, hasta que un día, y en un momento de inspiración, escribí yo solo un atroz vodevil, en medio acto, que le llevé a Chelito, y que ésta aceptó y puso en ensayo». Esta confidencia, sacada de una larga entrevista biográfica mantenida con el periodista Marino Gómez Santos (1969) en varios números del diario Pueblo (abril del 62), le dio base para una de las historietas que se cuentan en La niña de la calle del Arenal ${ }^{22}$, y en concreto para el asunto que aquí interesa: la narración de los comienzos teatrales de Edgar Neville en los años de la primera Gran Guerra y en el distendido y despreocupado Madrid. El Manolito que, tocado de canotié, sale a pasear por la Castellana recoge muchos de los recuerdos personales de Neville cuando frisaba entre los diecisiete y los veinte años. $M^{a}$ Luisa Burguera (1999) ha dado a conocer parte de una

22. Es el $n^{\circ} 31$ de La Novela del Sábado. En esta colección aparecieron textos de Luis Romero, Claudio de la Torre, Elena Quiroga, Tono, Noel Clarasó, Mingote, Zunzunegui, García Pavón, Carmen Nonell, etc. El n 29 fue, precisamente, el guión de la película ;Bienvenido, Mister Marshall! firmado por Berlanga, Bardem y Mihura. 
«Autobiografía» del autor en la que recuerda aquellos años, cuando jóvenes como él se entusiasmaban con los espectáculos del Chantecler y en especial con La Bella Chelito ${ }^{23}$. Son los años del couplet (una época que se empezaría a recuperar y a popularizar en los años cincuenta precisamente, gracias al cine de Juan de Orduña en colaboración con Sara Montiel), esa época en la que Neville ambientó su mejor título -en el doblete del teatro y del cine-como fue El baile, y del que hace una leve recreación al comienzo de la película La torre de los siete jorobados. En ese mismo documento antes citado leemos que el primer contacto de Neville con el teatro fue la cartelera del Cómico, además de las funciones del Teatro Apolo y las galas del Real. «Pero a los pocos años, ya vino el pantalón largo y los granos y los amigos del colegio y, naturalmente, la Chelito». Un recuerdo que se refleja tal cual en el comienzo del cap. III de la novelita en cuestión:

Existía el Chantecler. El teatrito de la Plaza del Carmen, donde se concentraba toda la picardía de la época [...] Manolito y sus compañeros de clase oían hablar a los mayores, a los de sexto año, de La Cielito. Esta era una de las mujeres más deliciosas que tuvieron las varietés españolas. Era una especie de colegiala escapada de clase que, con la sonrisa más inocente, cantaba canciones que no lo eran, y su pícara monería era tal que aún las canciones sin la menor intención parecían tener todos los diablos dentro de su letra (p. 20).

Y en el mismo lugar Neville evoca cómo eran aquellos espectáculos de un teatro de variedades en el que hizo su primer intento de ser famoso:

El espectáculo, que terminaba con su rumba y el milagro de súbitas revelaciones entre las vueltas del baile, lo componían unas coristas, bien entradas en carnes, que cantaban elucubraciones de quinto año de bachillerato a un público de horteras del mercado vecino, y, a veces, también daban un vodevil en medio acto, de título equívoco y en el que, como en las fiestas de los colegios, todos los actores eran mujeres y solo aparecía un único varón que, además de actor, era representante, regidor, tramoyista, pianista y recadero; también era el que cobraba los derechos de autor del vodevil ${ }^{24}$ (p. 21).

23. La cubana Consuelo Portela fue recreada por el escritor Joaquín Belda en su novela erótica La Coquito (1916)

24. En las referidas conversaciones con Gómez Santos, Neville recuerda que, cuando escribió uno de esos vodeviles de medio acto, «el día del ensayo general me llamó un curioso personaje que había en el teatro y que hacía a la vez de pianista, de administrador, de atrezista, de director de escena. Me hizo firmar un papel en el que le cedía todos los derechos de autor que pudieran derivarse de mi obra».De lo que también deja constancia en la novelita que comento: «Y el individuo, en un aparte, le 
En efecto, en aquella ocasión -1917- Neville escribió su primera obra, inédita, La vía láctea, vodevil de medio acto, estrenado en El Chantecler. De aquel primer logro nuestro autor evoca que la leyó «a mis compañeros de clase; a Pepe Martín, que luego me ha seguido en todas las andanzas posteriores cinematográficas, y otra serie de compañeros de colegio [...] y no recuerdo cómo llegué a ponerme en contacto con la Chelito y con doña Antonia, su madre, reina emperadora de El Chantecler». Y luego continúa contando cómo se preparó el ansiado estreno en términos prácticamente idénticos a los registrados en la novelita del 53. Compárese, si no:

[memorias] La lectura se verificó en El Infierno, que era una especie de «precabaret» localizado en los sótanos del teatro y sobre el mostrador del bar. A la lectura asistieron: Chelito, su madre, y un hombre que en aquel teatro lo hacía todo: tocaba el piano, era el tramoyista y representaba los únicos papeles de hombre que contenían los vodeviles en «medio acto»,

[novela] La lectura se celebró en un cabaret que estaba debajo del Chantecler y que se llamaba El Infierno, no se sabe si por hallarse debajo de tierra o por el calor que hacía en cuanto había en él más de doce personas. Pero la hora de la lectura fue las cuatro de la tarde, para que no estuviese absolutamente nadie más que los interesados, que eran la Cielito, el actor y una señora severa y enlutada emparentada con la artista (pp. 23-24).

No le fue fácil, con todo, a Neville este primer estreno, suscitado mitad por su ansias de fama, mitad por la atracción de la deliciosa cupletista de varietés. Tan subido de tono debió resultar la propuesta vodevilesca, que fue prohibida inmediatamente por la autoridad su representación. Y Neville (o Manolito en la ficción y todavía menor de edad) tuvo que ir a parlamentar con el mismo Director de Seguridad, para hacerse el interesante ante la vedette. En sus declaraciones a Gómez Santos, Neville recordaba el hecho con naturalidad, no poca nostalgia y un humor que le da encanto a la anécdota juvenil y teatral:

Por consejo de la madre de Chelito fui a verle personalmente, con mis libros de clase debajo del brazo. El director me recibió, y al saber mi pretensión me puso verde y me dijo que no levantaba la prohibición y

presentó un papel a la firma de Manolito en el que este renunciaba en su favor a los derechos de autor. Y como Manolito no perseguía el vil metal lo firmó, porque él solo quería el honor...» (p. 24). 
que volviera al colegio [...] Yo salí del despacho del director de Seguridad muy triste; pero luego, al llegar a la confluencia de la calle de la Reina con la de Hortaleza, comencé a interpretar las palabras de aquel buen señor en un sentido más amable. Al llegar a la red de San Luis me convencí a mí mismo que la entrevista había sido muy otra y que lo que había querido decir es que me volviera al colegio y que no persistiera en ese estilo dramático. Al desembocar en el callejón de San Alberto, el director había añadido ya en mi imaginación: Pero por esta vez puede pasar. Así es que, lleno de alegría, me asomé a la taquilla donde estaba doña Antonia, la madre de la Chelito, y le dije: Aprobado, se puede estrenar. ¡Y se estrenó!

En la novelita -p. 27--el suceso se cuenta de forma prácticamente idéntica y, naturalmente, que acaba teniendo su correlato en el texto memorialístico (entrevista, memorias y novela son absolutos vasos comunicantes).

Pero vayamos a lo importante que es la representación de aquel primer vodevil. En este punto novela y memorias difieren, pues en las segundas Neville se extiende en detalles que en La niña... reduce a un breve párrafo, de modo que tenemos que acudir al texto inédito (hasta que lo publicó $\mathrm{M}^{\mathrm{a}}$ Luisa Burguera) para saber algo más concreto de La vía láctea en la única representación que le cupo tener. El «verdadero triunfo» que se dice en la novela corta se explaya en este párrafo de la autobiografía, que vale por todo un documento acerca de cómo era el teatro ligero, el «teatro de varietés» de aquellos años madrileños:

El estreno fue sensacional, las localidades de El Chantecler estaban llenas de ese público distinguido que eran los habitués de los estrenos, la flor y nata de los pescaderos del Mercad del Carmen, la juventud de las cercanías, los estudiantes de provincias de la casa de huéspedes de la calle Hita, y luego una serie de sujetos estrafalarios que iban desde el anciano no venerable hasta el organillero y el señorito en noche de francachela. Para agravar las cosas, era sábado por la noche y los sábados por la noche, en la plaza del Carmen, eran algo tremendo. Por fin llegó la hora y se levantó el telónapareciendo la escena lujosamente ataviada. El lujo consistía en un paravant y en una chaise-longue, en la escena, ni había más muebles ni cabían más, pero estaban puestos con tanta gracia que produjo un murmullo de admiración. Al poco tiempo, se presentaba la Chelito y decía «¿Está el doctor?»,y entonces los pescaderos que ocupaban el palco platea gritaban a coro: «iSí!, está el doctor, vaya quitándose la ropa». La Chelito les sonreía como celebrando aquella ingeniosidad y los pescaderos, domados por el encanto de esta mujer, enmudecían, pero al poco tiempo salía el doctor con una barba 
blanca verdaderamente inaceptable, y entonces todos los gremios del Mercado del Carmen comenzaban a meterse con él y con su barba y a partir de ese momento no se oía nada del diálogo, todo se convirtió en una especie de película muda en la que la Chelito se quitaba un abrigo y después seguía según las indicaciones de la obra.

Aunque la cita es larga, he preferido transcribirla entera porque es una de las escasísimas noticias que tenemos de este texto de la prehistoria literaria de Neville, que se adelantó nueve años a su primera colección narrativa, Eva y Adán. Sobre todo porque en aquel lúdico y ruidoso happy-end se perdió todo el encanto de la picaresca y del doble sentido que los diálogos al parecer tenían y que habían sido escritos con tanta ilusión por un adelantado colegial. Fue el medio sueño de una noche de estreno que se agotó al día siguiente cuando -se cuenta en todos los registros-en el teatro del callejón de San Ricardo (donde hoy se alza el teatro Muñoz Seca) figuraba ante la taquilla cerrada el cartel de supresión indefinida de la obra por orden de la Autoridad.

En los capítulos siguientes de La niña de la calle del Arenal se siguen refiriendo diversos aspectos de las varietés de la época, y el personaje de ficción del relato, el Manolito en el que se proyecta Neville en la nostalgia de su juventud pasada, se relaciona con sobresalientes figuras de aquel mundo, como Raquel Meller, la Fornarina, la Argentinita, Olimpia D'Avigny o Mercedes Serós, todas ellas figuras del Trianon Palace o del Romea $^{25}$ (otros teatros del género) y salen a relucir las historias entre sentimentales y picantes de los couplets con las letras del pintor y dibujante Juan Martínez Abades $^{26}$. Y cuando el mismo Madrid era, en sus calles, en sus tipos, un escenario colorista y vívido, o un excelente estudio cinematográfico, en el momento en que la Primera Gran Guerra daba paso a los alegres años veinte. Este cuadro que figura en la p. 59 de la novelita es copartícipe del Madrid que entrevemos en su cine (La torre..., Domingo de Carnaval, El crimen de la calle de Bordadores y, especialmente, Mi calle o en el poema en redondillas $\left\langle\right.$ Mi barrio ${ }^{27}$ )

25. Considerado la catedral del género cupletista, situado en la calle Alcalá, entre Sevilla y Nicolás María Rivero (actual Cedaceros). Frente al Trianón surgió su máximo competidor, el reconvertido teatro Romea, situado en Carretas y propiedad de Alexanco.

26. A él se deben la letra y música de «Mimosa», «Flor de té», «Mala entraña», «Amor de muñecos», «Agua que no has de beber» $\mathrm{o}$ «iAy, Cipriano!».

27. «Encarna divina/divina Raquel./ Silencio, ha llegado/la era del cuplé [...] Butaca de orquesta, / del viejo Romea,/ café de Levante,/ humo que marea [...] Palco de abonados/ pasados de 
Manolito, desde el baicón de su casa de la plaza de las Descalzas, veía, sin darse cuenta, los últimos personajes de aquel mundo pausado. La facilidad para subsistir producía unos seres atrabiliarios que más tarde serían difíciles de encontrar. Los mendigos medio locos; aquel Garibaldi cubierto de medallas que gritaba «iArriba Caballo Moro!» en un delirio de Valdepeñas, la «Tonta de la Pandereta», con su baile espantoso que terminaba con unas velocísimas vueltas mientras tocaba su instrumento. «Madame Pimentón» con su sombrero extravagante, su bolso y su miseria ${ }^{28}$. Y luego ese rumor de la calle de barrio madrileño, con los vendedores ambulantes que gritaban su pregón desde el centro del arroyo, sin miedo a ser atropellados por los coches de caballos cuyos cascos sacaban estrellas en el duro empedrado de aquel Madrid. Y todo ello con una música de fondo, con el «Hombre Orquesta», que tocaba a la vez diez o doce instrumentos, y con los organillos, que eran la radio del tiempo y que popularizaban las canciones a la moda, y los pobres que pedían limosna por malagueñas, acompañándose con unas guitarras que sonaban también a pobre, $y$ todo aquello escuchado por las criadas que sacudían las alfombras en los balcones y se enamoraban de los organilleros...

edad,/detallan con lupa/gracias de verdad [...] Mas tienen un gesto/ de desinterés,/ellos les define/ como habitués» (Neville, 1969 , pp. 828 y 829 ).

28. Este personaje, atrabiliario donde los hubiera, debió alcanzar una tremenda popularidad en la capital todavía demasiado provinciana, a juzgar por el retrato que nos hace de ella $\mathrm{M}^{\mathrm{i}}$ Teresa León en su Memoria de la Melancolia, en un relato que lleva su nombre como título y en un personaje de la interesante y simbólica pieza teatral de exilio La libertad en el tejado. 


\section{BIBLIOGRAFÍA}

Benito, Jesús de. «Producciones García S.A.» en Edgar Neville 100 (Nickel Odeon, 17, 1999, pp. 235-236).

Burguera Nadal, María Luisa. Edgar Neville entre el humor y la nostalgia. Valencia, Institució Alfons el Magnánim y Universitat Jaume I, 1999.

García Fuentes, Enrique. «Dos ediciones de Don Clorato de Potasa» Anuario de Estudios Filológicos. UNEX, XIII, 1990, pp. 111-121.

Gómez Santos, Marino. Doce hombres de letras. Madrid, Editora Nacional, 1969.

Neville, Edgar. La familia Mínguez. Barcelona, Janés, 1946 y Madrid, Afrodisio Aguado, 1957.

. La niña de la calle del Arenal. Madrid, Tecnos, 1953. . Torito Bravo. Barcelona, José Janés, 1955 (el cuento mencionado se recogió luego en el volumen de Obras Selectas referido en una entrada posterior).

. Producciones García S.A. Madrid, Taurus, 1956. - La piedrecita angular. Madrid, Taurus, 1957. . Obras Selectas. Madrid, Biblioteca Nueva, 1969. 